\title{
Magnetic resonance imaging of anterior cruciate ligament rupture Kai-Jow Tsai ${ }^{1}$, Hongsen Chiang ${ }^{2}$ and Ching-Chuan Jiang*2
}

\author{
Address: ${ }^{1}$ Department of Orthopaedic Surgery, Cathay General Hospital, Taipei, Taiwan and ${ }^{2}$ Department of Orthopaedic Surgery, National \\ Taiwan University Hospital, Taipei, Taiwan \\ Email: Kai-Jow Tsai - tsaikj@ms2.hinet.net; Hongsen Chiang - hongsen@ha.mc.ntu.edu.tw; Ching-Chuan Jiang* - ccj@ccms.ntu.edu.tw \\ * Corresponding author
}

Published: 08 July 2004

BMC Musculoskeletal Disorders 2004, 5:21 doi:10.1 186/147|-2474-5-21

This article is available from: http://www.biomedcentral.com/I47I-2474/5/2I
Received: 22 July 2003

Accepted: 08 July 2004

(C) 2004 Tsai et al; licensee BioMed Central Ltd. This is an Open Access article: verbatim copying and redistribution of this article are permitted in all media for any purpose, provided this notice is preserved along with the article's original URL.

\begin{abstract}
Background: Magnetic resonance (MR) imaging is a useful diagnostic tool for the assessment of knee joint injury. Anterior cruciate ligament repair is a commonly performed orthopaedic procedure. This paper examines the concordance between MR imaging and arthroscopic findings.

Methods: Between February, 1996 and February, 1998, 48 patients who underwent magnetic resonance (MR) imaging of the knee were reported to have complete tears of the anterior cruciate ligament (ACL). Of the 48 patients, 36 were male, and 12 female. The average age was 27 years (range: 15 to 45). Operative reconstruction using a patellar bone-tendon-bone autograft was arranged for each patient, and an arthroscopic examination was performed to confirm the diagnosis immediately prior to reconstructive surgery.

Results: In 16 of the 48 patients, reconstructive surgery was cancelled when incomplete lesions were noted during arthroscopy, making reconstructive surgery unnecessary. The remaining 32 patients were found to have complete tears of the $A C L$, and therefore underwent reconstructive surgery. Using arthroscopy as an independent, reliable reference standard for $A C L$ tear diagnosis, the reliability of $M R$ imaging was evaluated. The true positive rate for complete $A C L$ tear diagnosis with MR imaging was $67 \%$, making the possibility of a false-positive report of "complete ACL tear" inevitable with MR imaging.
\end{abstract}

Conclusions: Since conservative treatment is sufficient for incomplete ACL tears, the decision to undertake $A C L$ reconstruction should not be based on $M R$ findings alone.

\section{Background}

The approach taken with an ACL injury depends a great deal on the severity of the lesion. Complete ACL tears usually cause considerable knee joint instability and reconstructive surgery is typically recommended. In contrast, a partial ACL tear can be treated with physical rehabilitation alone. Since reconstructive surgery involves significant remodeling, confirmation of the diagnosis is desirable before undertaking unnecessary surgery on patients with incomplete ACL tears.
An arthroscopic examination allows the diagnosis to be confirmed through direct visualization and probing. Unfortunately, arthroscopies are invasive and require a skilled surgeon. MR imaging has become a popular and practical tool for the evaluation of ACL injuries, with it's a high degrees of accuracy and sensitivity reported in the literature $[1,2]$. Notwithstanding its accuracy and sensitivity, the potential for false-positive reports make reconstructive surgery unjustifiable based on MR findings alone $[3,4]$. In cases where complete ACL tears have been diagnosed with MR imaging, the authors' have found incomplete lesions 
on arthroscopic examination immediately prior to planned reconstructive surgery. In these situations, reconstructive surgery was cancelled and substituted with a program of rehabilitation. This study aimed to evaluate the accuracy of MRI in diagnosing complete ACL ruptures in the knee.

\section{Methods}

Between February 1996 and February 1998, forty eight patients with clinically suspected ACL injury were reported to have complete ACL tears on MR imaging. Of the 48 patients, 36 were males and 12 female, and patients ranged between 15 and 45 years in age (mean: 27.7 years). In all cases the injuries were unilateral, with 22 affecting the right knee and 26 the left knee. Seventeen patients had injured themselves playing basketball. The patients all underwent manual Lachman test examination by the senior author (Jiang). Three experienced radiologists interpreted the MR images.

Arthroscopic examinations were performed in order to confirm the diagnosis prior to reconstructive surgery. A complete tear of the ACL is diagnosed arthroscopically if the ligament is absent in the intercondylar notch region, or if there is loss of ligament continuity with only ligamant remnants at each end. In cases where continuity of one or both bundles of the ligament was present and laxity of the ligament was noted by probing, the injury was defined as a partial tear. The integrity of the joint menisci was also assessed during the arthroscopy.

Once a complete tear of the ligament was confirmed arthroscopically, the surgeon proceeded directly to reconstructive surgery in the same theatre using a patellar bonetendon-bone autograft. All arthroscopies and reconstructions were performed by the same surgeon (Jiang).

\section{Results}

Thirty-two of the forty eight patients were found to have complete ACL tears during arthroscopy, while the remaining patients were found to have partial tears. Given that MR imaging diagnosed complete tears in all of the patients, the true-positive rate for the MR examination was $67 \%$. The ratio differed among the reporting radiologists, being $82 \%, 54 \%$, and 50\% respectively. The experienced radiologist have the higher accuracy in this study.

The Lachman test was positive in 39 cases, among which 30 had complete tears of the ACL arthroscopically proven, while the others were shown to have incomplete lesions. The Lachman test was negative in nine patients, among which seven were found to have partial tears of the ACL arthroscopically. The true-positive rate for the Lachman examination was $77 \%$.
Associated meniscal tears were present in 34 patients (71\%). Lateral meniscal tears were present in 22 patients (46\%), and medial meniscal tears were present in seven patients $(14 \%)$. Tears to both menisci were present in the remaining five patients $(11 \%)$.

\section{Discussion}

The MR imaging report influences clinical decision making and has medico-legal implications. If the surgeon depends solely on the report for the decision to go to surgery, false positive reports may lead to unnecessary procedures.

Most orthopaedic surgeons currently advocate the use of an autograft for reconstruction of a completely torn ACL. In contrast, a knee joint with a partially torn ACL that exhibits moderate instability may function well after well planned rehabilitation. Since reconstructive procedures involve unavoidable and substantial remodeling of the donor structure, the diagnosis should be confirmed before proceeding with reconstructive surgery.

Arthroscopies, via direct vision and probing of the ACL, allow for reliable assessment of the extent of ACL injury, but are invasive and require an experienced surgeon [2]. MR imaging allows the structures of the knee joint to be visualized, including the ACL, while avoiding the need for surgical intervention and irradiation, and can help to prevent unnecessary diagnostic arthroscopic procedures in acute knee injuries. The reported sensitivity of MRI for acute ACL tears is 90\% [5]. MRI is now widely used for the detection of intra-articular lesions, but in the experience of the authors, false positive reports can lead to overenthusiastic surgery.

The statistical conception of test accuracy is a summation of its true-positive and true-negative rates. Thus a test with high true-negative and fair true-positive rates may still be very accurate. However, a high true-positive rate is critical for tests upon which a decision to surgically intervene is made. MRI has been reported to have a high accuracy in diagnosing internal derangements of the knee. Machenzie et al reviewed 22 related reports between 1983 and 1994 and found a high accuracy in diagnosing ACL lesions, ranging from 72 to 100 percent. Amongst a total of 2076 subjects there were 498 positive diagnoses, of which 90 were false-positives [6].

The high reported accuracy of MRI has been debated since most of the reported results were based on retrospective, non-blind study designs [6]. In these reports, the patients who underwent MR examination were those who were suspected of having an ACL lesion, based on clinical assessment $[1,7]$. The Lachman test has been reported to be a very accurate clinical examination for both acute and 


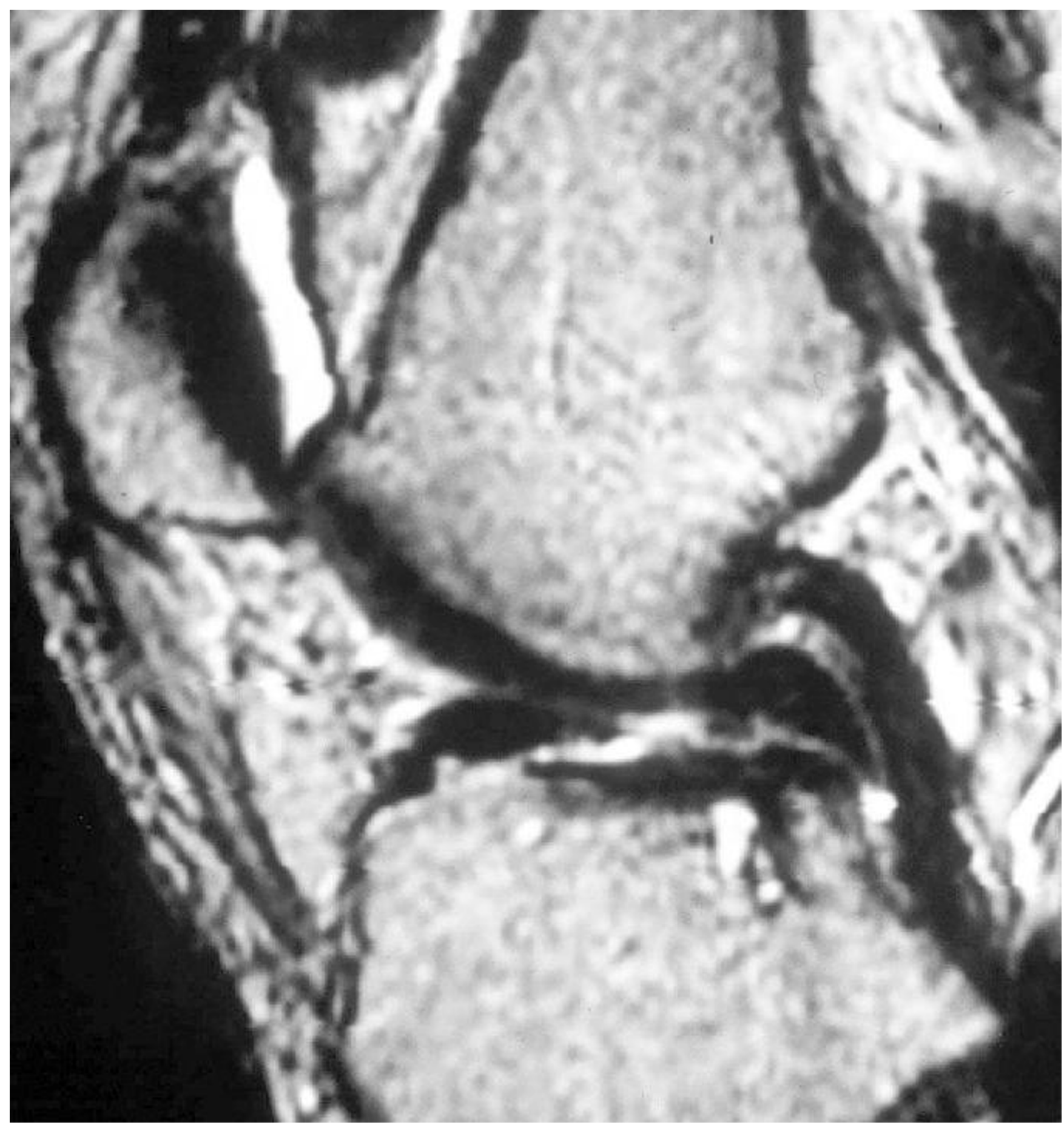

Figure I

A twenty-five-year-old female suffering from internal derangement of the left knee. The MRI report described $A C L$ rupture due to poor visualization of the $A C L$ substance. 


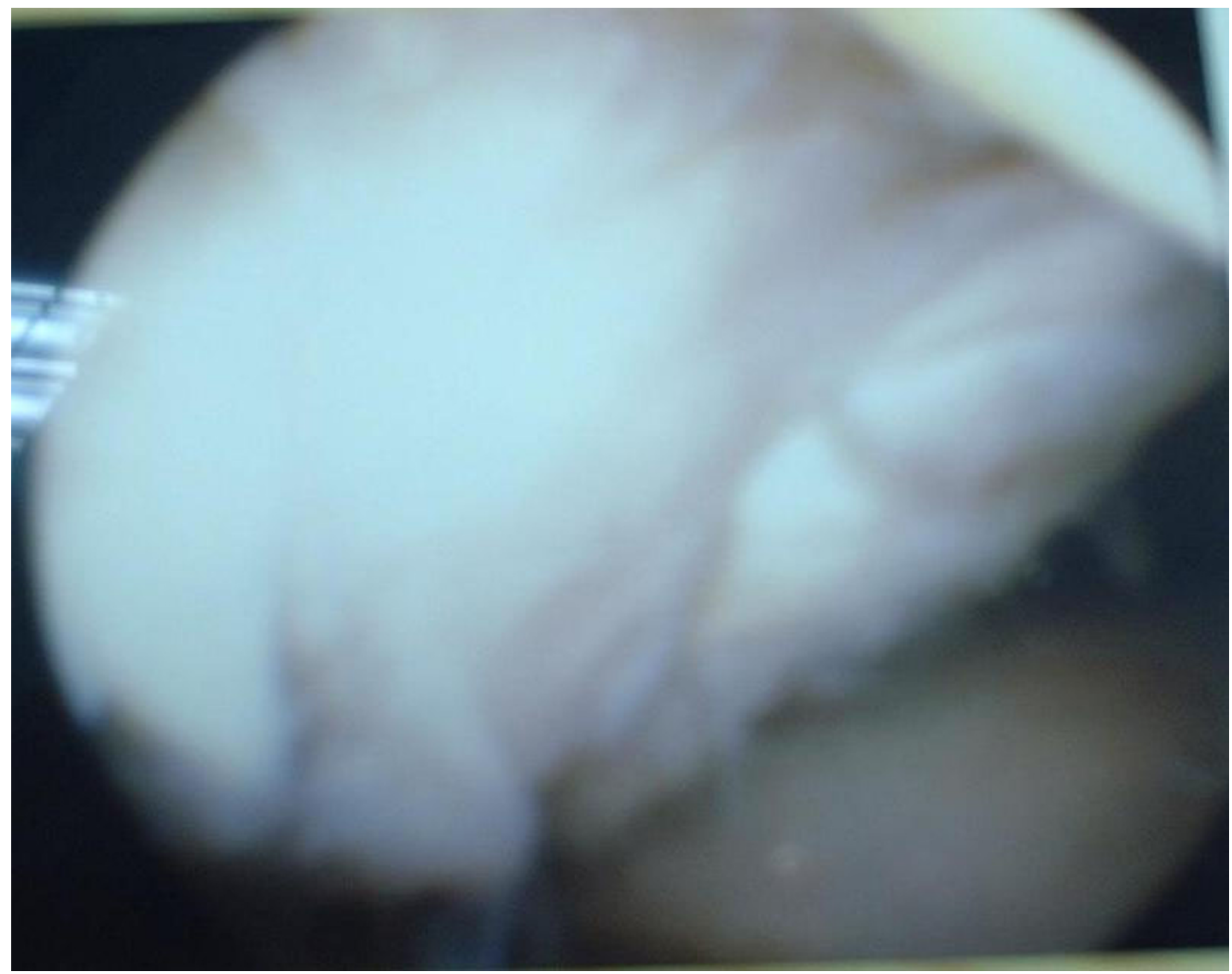

Figure 2

On arthroscopic examination, the ACL was found to be intact.

chronic ACL deficiency, with a sensitivity and specificity ranging between 85 and 98 percent [8]. In cases involving chronic tears, the scarred fragments produce a relatively straight band that mimics an intact ligament [9]. There are several factors that may contribute to the discrepancy found between arthroscopic findings and MR imaging reports. The interpretation of MR images may be influenced by the imaging equipment, techniques, and subjective bias of the reading radiologists. Katahira reported that the addition of thin slice direct oblique coronal images significantly improved the accuracy of ACL tear diagnosis, from $82 \%$ to $97 \%$ [10]. Murao has reported a quantitative method involving the ACL-tibial plateau angle as a means of improving diagnostic accuracy [11]. The two-bundle construction of the ACL may also lead to a positive report on $\mathrm{MR}$, in cases where only one torn bundle is seen on the image, while the remaining intact bundle is overlooked or not imaged between subsequent MR slices $[12,13]$.

An ligament with a so-called "substance tear" indicates an injury within the ligament itself. It is the tomographic nature of MR that makes the interior of the ligament visible. A developing technique, the intra-articular arthroscopic ultrasound, may eliminate this failing of arthroscopic examination.

This paper has not sought to debate the value and accuracy of MR in the diagnosis of ACL injuries. The key issue is the difference in strategies for treating complete versus incomplete lesions, and how this makes confirmation of 
the diagnosis important, since false-positive MR reports can not be confidently excluded. To avoid unnecessary surgery, the decision to undertake ligament reconstruction should not be based on imaging alone $[1,14]$.

The surgical decision should also depend on physical findings and clinical symptoms [15]. Imaging should support the clinical findings and inform surgical planning, and arthroscopic examination should be used to confirm the diagnosis before reconstruction $[4,16]$.

In conclusion, an ACL tear suspected on the basis of clinical findings or MRI should have the diagnosis confirmed arthroscopically, especially when ligament reconstruction is envisaged.

\section{Competing interests}

None declared.

\section{Authors' contributions}

KJT: Collect data, analysis the result and write the paper.

\section{HC: Revise the paper.}

CCJ: The senior surgeon, operate all the patients and give the original idea.

\section{References}

I. Boeree NR Watkinson AF, Ackroyd CE, Johnson C.: Magnetic resonance imaging of meniscal and cruciate injuries of the knee. J Bone Joint Surg [Br] 1991, 73-B:452-457.

2. Fischer SP Fox JM, Del Pizzo W, Friedman MJ, Snyder SJ, Ferkel RD.: Accuracy of diagnoses from magnetic resonance imaging of the knee. J Bone Joint Surg [Am] I991, 73-A:2-I0.

3. Jackson DW Jennings LD, Maywood RM, Berger PE.: Magnetic resonance imaging of the knee. Am J Sports Med 1988, 16:29-38.

4. Liu SH Osti L, Henry M, Bocchi L.: The diagnosis of acute tears of the anterior cruciate ligament: comparison of MRI, arthrometry and clinical examination. J Bone Joint Surg $[\mathrm{Br}]$ 1995, 77B:586-588.

5. Munshi M Davidson M, MacDonald PB, Froese W, Sutherland K.: The efficacy of magnetic resonance imaging in acute knee injuries. Clinical J Sport Med 2000, I 0(I):34-39.

6. Machenzie R Palmer CR, Lomas DJ, Dixon AK: Magnetic resonance image of the knee: diagnostic performance statistics. Clinical radiology 1996, 5 I:25 I-257.

7. KE DeHaven: Diagnosis of acute knee injuries with hemarthrosis. Am J Sports Med 1980, 8:9-14.

8. Donaldson WF Warren RF, Wickiewicz T.: A comparison of acute anterior cruciate ligament examinations: initial versus examination under anesthesia. Am J Sports Med 1985, 13:5-10.

9. Vahey TN Broome DR, Kayes KJ, Shelbourne KD.: Acute and chronic tears of the anterior cruciate ligament: differential features at MR imaging. Radiology 1991, I 81:251-253.

10. Katahira K Yamashita Y, Takahashi M. Otsuka N., Koga Y. Fukumoto T., Nomura K.: MR imaging of the anterior cruciate ligament: value of thin slice direct oblique coronal technique. Radiation Medicine 200I, 9(I): I-7.

II. Murao H Morishita S, Nakajima M, Abe M.: Magnetic resonance imaging of anterior cruciate ligament (ACL) tears: diagnostic value of ACL-tibial plateau angle. J Orthopaedic Science I998, 3(I): I0- 17.

12. Barry KP Mesgarzadeh M, Triolo J, Moyer R, Tehranzadeh J, Bonakdarpour A.: Accuracy of MRI patterns in evaluating anterior cruciate ligament tears. Skeletal Radiol 1996, 25:365-370.
13. Remer EM Fitzgerald SW, Friedman H, Rogers LF, Hendrix RW Schafer MF.: Anterior cruciate ligament injury: MR imaging diagnosis and patterns of injury. Radiographics 1992, I 2:901-915.

14. Spiers AS Meagher T, Ostlere S], Wilson DJ, Dodd CA.: Can MRI of the knee affect arthroscopic practice? A prospective study of 58 patients. J Bone Joint Surg [Br] 1993, 75-B:49-52.

I5. Jonsson T Althoff $B$, Peterson $L$, Renstrom P.: Clinical diagnosis of ruptures of the anterior cruciate ligament: a comparative study of the Lachman test and the anterior drawer sign. Am J Sports Med 1982, 10:100-102.

16. Rappeport ED Wieslander SB, Stephensen S, Lausten GS, Thomsen HS.: MRI preferable to diagnostic arthroscopy in knee joint injuries. A double-blind comparison of 47 patients. Acta Orthopaedica Scandinavica 1997, 68(3):277-281.

\section{Pre-publication history}

The pre-publication history for this paper can be accessed here:

http://www.biomedcentral.com/1471-2474/5/21/prepub
Publish with Bio Med Central and every scientist can read your work free of charge

"BioMed Central will be the most significant development for disseminating the results of biomedical research in our lifetime. "

Sir Paul Nurse, Cancer Research UK

Your research papers will be:

- available free of charge to the entire biomedical community

- peer reviewed and published immediately upon acceptance

- cited in PubMed and archived on PubMed Central

- yours - you keep the copyright 